\title{
DANIEL 1:3-7: \\ INTERESES REALES E \\ IMPLICANCIAS EN \\ RELACIÓN AL SACERDOCIO HEBREO/BABILONICO
}

LiC. JOEL BENÍTEZ

Asociación Venezolana de Los Llanos Occidentales Venezuela 


\title{
Resumen
}

Daniel 1:3-7: Intereses reales e implicancias en relación al sacerdocio hebreo/babilonico. La extensa literatura en conexión al libro de Daniel presenta como postura tradicional, la intencionalidad del rey en convertir a los jóvenes hebreos en vasallos reales. Sin embargo, el presente escrito busca ampliar la interpretación tradicional a una valoración de éste en el plano sacerdotal. La función del rey se convertía en un medio para controlar y monitorear cada aspecto religioso del reino. De esta forma se afirman las bases para esta última y posible forma interpretativa, o incluso para la fusión de ambas posiciones como un acto de formar oficiales aptos para el beneficio de la estructura de reino, ya sea a nivel político, civil y religioso.

Palabras clave: Sacerdocio, realeza, templo.

\begin{abstract}
Daniel 1:3-7: Royal Interests and Implications Related to the Hebrew/Babylonian Priesthood. The extensive literature regarding the book of Daniel presents as a traditional view, the intention of the king in order to convert the young Hebrews as royal vassals. However, this article pretends to amplify the traditional interpretation toward a sacerdotal view. The role of the king becomes a means to control and monitor every aspect of the religious life of the kingdom. In this way, the foundations for this last and possible interpretation, or even for the fusion of both perspectives as an act of forming officials for the benefit of the kingdom structure, either for the political, civil and religious levels.
\end{abstract}

Keywords: Priesthood, royalty, temple.

Recibido: $14 / 07 / 2021$

Aceptado: 07/10/2021 
Estrategias para el Cumplimiento de la Misión 19, no. 1 (2021): 83-96

\title{
DANIEL 1:3-7: INTERESES REALES E IMPLICANCIAS EN RELACIÓN AL SACERDOCIO HEBREO/BABILONICO
}

\author{
Lic. JOEL BeNíTEZ \\ Asociación Venezolana de Los Llanos Occidentales \\ Venezuela
}

\section{Introducción}

Daniel, en su primer capítulo, presenta una variedad de aspectos introductorios de gran importancia para la comprensión de toda la obra. ${ }^{1}$ Su estudio permitirá aclarar y fundamentar las bases para una mejor comprensión de los aspectos históricos y proféticos que se registran en el volumen. ${ }^{2}$ De esta manera, crece el interés por dilucidar en amplia escala los elementos cúlticos-rituales y su relación con el santuario-sacerdocio.

De esta manera, al estudiar los vv. 3-7 del capítulo 1 de Daniel, encontramos dos formas de interpretar las intenciones del rey. En la primera, pareciera que el monarca trae a los jóvenes hebreos, solo para educarlos en cada aspecto de la realeza, procurando su desarrollo como estadistas, asesores y reyes vasallos. ${ }^{3}$ Pero en la segunda, existe la probabilidad de un fuerte deseo por convertirlos en sacerdotes oficiantes

1 Hans J. M. van Deventer, “The Function of Daniel 1 in a Second Century BCE Historical Context", The Journal for Transdisciplinary Research in Southern Africa 7, no. 2 (2011): 227; Greg Goswell, “The Temple Theme in the Book of Daniel”, JETS 55, no. 3 (2012): 509-520; George A. Barton, "The Composition of the Book Daniel", JBL 17, no. 1 (1898): 62-86.

2 Francis Gigot, "El libro de Daniel”, Enciclopedia Católica Online, disponible en https://ec.aciprensa.com/wiki/Libro_de_Daniel (consultado: 01 de noviembre, 2021).

3 Larry Pechawer, Poetry and Prophecy (Cincinnati, OH: Standard Publishing, 2008), 214; Andrew E. Hill, "Daniel”, The Expositors Bible Commentary, ed. Tremper Longman III y David E. Garland (Grand Rapids: Zondervan, 2008), 8:49; John F. MacArthur, The MacArthur Bible Commentary (Nashville: Nelson, 2005), 949; Michael Whitworth, The Derision of Heaven: A Guide to Daniel (Brandford, FL: Start2finish, 2013), 20-22.

https://doi.org/10.17162/recm.v19i1.1473 
de la vida cultual de Babilonia. ${ }^{4}$ Frente a estas dos propuestas surgen algunas interrogantes: ¿Existen elementos de apoyo para este segundo planteamiento? ¿Es posible bosquejar la idea del doble interés del rey por convertirlos en ambos propósitos, y así formarlos para su utilidad, según las necesidades del reino? A continuación se describen los diferentes aspectos que se hallan en el texto en conexión con el contexto histórico para poder definir los propósitos del rey para con los jóvenes hebreos.

\section{Diferentes opiniones en relación al contexto histórico en el plano real- sacerdotal según Daniel 1:3-7}

Como posición tradicional, se desarrolla la idea de un propósito definido relacionado a una capacitación para el servicio real, ya sea como estadistas, asesores y reyes vasallos, ${ }^{5}$ o como súbditos verdaderos, ${ }^{6}$ teniendo como punto de partida una selección que los conforma como jefes representativos de una clase especifica. ${ }^{7}$ Basado en esta hipótesis, estos jóvenes no podrían ser aceptados en la clase sacerdotal, siendo que han sido tomados como hombres sabios. En este sentido, el planteamiento de la Escritura en torno a los acontecimientos narrados en el capítulo 1 de Daniel muestra una labor de consejería basado en la ciencia de la sabiduría. De ser así, la posibilidad de una conexión sacerdotal no sería posible. ${ }^{8}$

Sin embargo, y de forma opuesta a esta opinión, se presenta la conjetura en conexión al plan de convertir a los jóvenes hebreos en verdaderos sacerdotes caldeos, expertos en la ciencia de la adivinación. ${ }^{9}$ De ser así, este

4 Jacques B. Doukhan, Secretos de Daniel: Sabiduría y sueños de un príncipe judí en el exilio (Florida: Asociación Casa Publicadora Sudamericana, 2008), 17.

5 John H.Walton, Victor H. Matthews y Mark W. Chavalas, Comentario al contexto cultural de la biblia (Colombia: Mundo Hispano, 2004), 828; Miguel Ángel Tabet, Benito Marconcini y Giovanni Boggio, Introducción al Antiguo Testamento II: Libros Proféticos (Madrid: Ediciones Palabra, 2009), 406; Aarón B. Hebbord, Reading Daniel as a Text in Theological Hermeneutics (Eugene, OR: Pickwick, 2009), 67-70; Pechawer, Poetry and Prophecy, 214; Hill, "Daniel", 49; MacArthur, The MacArthur Bible Commentary, 949; Whitworth, Derision of Heaven, 20-22.

6 Merling Alomía, Daniel: El profeta mesiánico (Perú: Theologika, 2007), 21.

7 Wood J. Leon, A Commentary on Daniel (Eugene, OR: Wipf \& Stock,1998), 40.

8 G. Ch. Aalders, "The Book of Daniel: Its Historical Trustworthiness and Prophetic Character", EvQ 2, no. 3 (1930): 242-254.

9 Doukhan, Secretos de Daniel, 17.

https://doi.org/10.17162/recm.v19i1.1473 
sería un intento de adulterar el gran plan de salvación en relación a la verdad bíblica. ${ }^{10}$ Incluso, se ha propuesto que en Babilonia se confunde el poder sacerdotal con el civil, pareciendo fusionarse ambos entre sí. ${ }^{11}$ Es por esta razón, que los estudiosos ven a Daniel y a sus tres amigos como superiores a los expertos religiosos en la corte del rey. Con esto en mente, variedad de pensamientos es evaluada por R. Glenn Wooden, el cual propone que este último argumento no es tan claro; sin embargo, es posible rastrear la idea de que estos profesionales podían tener relación religiosa y administrativa a la vez. ${ }^{12}$

\subsection{Vida sacerdotal en Babilonia}

En Babilonia, no cualquiera podía ser sacerdote del templo babilónio. Para ser escogido como tal, el candidato para este oficio debía ser examinado para ser catalogado como especialista en inteligencia y brillo. ${ }^{13}$ Debían nacer de una línea genealógica particular y sus padres tenían que haber sido sacerdotes. Estos se constituían en requisitos esenciales a la hora de consagrarlos para el servicio religioso. Además, acceder a este ritual de consagración era esencial para lograr acceso al templo. Por esta razón, existía un sumo sacerdote quien estaba facultado para acceder a la presencia de los dioses y con la responsabilidad de cuidar de ellos. Este, junto a los demás sacerdotes, tenía que ser sin defecto alguno, evitando ser descalificado para dicho oficio, además de tener perfección de la mente. ${ }^{14}$ Sin lugar a duda, estas características también están presentes como exigencias del rey Nabucodonosor para los exiliados, dando a entender que éste se regía por el patrón de las costumbre del Oriente medio. Esto es evidente no solo por los meticulosos requerimientos académicos que exigía,

10 Warren A. Shipton, "La perspectiva de Daniel sobre la historia, la filosofía y destino", Dialogo Universitrio 25, no. 1 (2013): 13-17.

11 Carlos Miguel Buela, Sacerdotes para siempre (New York: IVE Press, 2011), 146.

12 R. Glenn Wooden, The Book of Daniel and Manticism: A Critical Assessment of the View that the Book of Daniel Derives from a Mantic Tradition (PhD Dissertation, University of St. Andrews, 2000), 102. Daniel es ampliamente asociado con los adivinos en base a su posición descrita en los capítulos 2, 4 y 5 del libro que lleva su nombre y dicha postura es mantenida en la tradición. R. Glenn Wooden, "The Recontextualization of Old Greek Daniel 1", en Of Scribes and Sages: Early Jewish Interpretation and Transmission of Scripture - Volume 1: Ancient Versions and Traditions, SSEJC 9 (New York: T\&T Clark, 2004), 48

13 Peter J. Leithart, "Priests of Babylon", https://www.patheos.com/blogs/leithart/2015/ 01/priests-of-babylon/ (consultado: 01 de noviembre, 2021).

14 Ibíd. 
sino también por lo detallista que llegó a ser a la hora de asignar la alimentación de los jóvenes en preparación; sin que ésta fuera, en su opinión, dañina en lo moral o físico, ${ }^{15} \mathrm{y}$ teniendo en cuenta que todos los aspectos de la vida estaban vinculados a la religión. ${ }^{16}$

De esta forma, los rituales cobraban vital importancia porque involucraba la renovación política del rey como gobernante legítimo, siendo parte fundamental del programa ideológico de la monarquía y el clero. ${ }^{17}$ De esta manera se formaba el clero de Marduk, ${ }^{18}$ altamente preparado con los estándares del colegio sacerdotal. Es en dicha escuela, en donde sus estudiantes llegan a conocer con claridad y cabalidad sus atribuciones. Así, con este nivel de influencia del sistema de preparación, se intentaba ocultar las opiniones monoteístas de los jóvenes hebreos, puesto que todo poder y riqueza dependían del culto tradicional politeísta, altamente diferente al de Jerusalén. ${ }^{19}$

\subsection{La realeza en conexión al sacerdocio babilónio}

El vínculo del rey con el sacerdocio es imposible de desligar, siendo que éste se erige como soporte y protección de la institución religiosa. Para lograr cumplir con su responsabilidad espiritual, el monarca se convierte en un devoto fiel de las diferentes deidades del imperio. ${ }^{20}$ Así conseguía controlar todas las esferas de su gobierno. El rey, en plena función de sus facultades, lograba instituir a los miembros del clero. Del mismo modo, participaba en las procesiones y fiestas programadas, integrando a los sacerdotes en su lista de funcionarios reales. Con este registro, no era raro ver entre los más altos líderes del clero a miembros de la casta real, relacionados al interés de cuidar de cerca los grandes y suntuosos templos

15 Evis L. Carballosa, Daniel y el reino mesiánico (Grand Rapids: Portavoz, 1979), 44.

16 Luigi Cagni, "Mesopotamia”, Diccionario Akal de las Religiones, ed. Giovanni Filoramo (Madrid: Ediciones Akal, 2001), 369.

17 Carlos Fernández Rodríguez, "La exaltación de la divinidad en Mesopotamia: Marduk y Sin, dos posibles instrumentos políticos en Babilonia", Revista Historia Autonoma 10 (2017): 18-19.

18 Carlos G. Wagner, Historia del Cercano Oriente (Salamanca: Ediciones Universidad de Salamanca, 1999), 275.

19 Karl Kautsky, El cristianismo: Sus orígenes y fundamentos (Barcelona: Círculo Latino, 2006), 237.

20 G. Ernest Wright, Arqueología Bíblica: Colección Sagrada Escritura (Madrid: Cristiandad, 2002), 309. 
del imperio. ${ }^{21}$ Así, con esta amplia evidencia, es posible aceptar la idea de que las cortes reales de Babilonia servían de albergues para sabios y poetas que ejercían, tanto en la línea sacerdotal como en la real.22

Entonces, no habría razón para presumir que los sacerdotes babilonios, fueran más atrasados que los egipcios, sino que parecen estar en igualdad tanto en las artes como en las ciencias. ${ }^{23}$ Esto queda percibido por los registros arqueológicos encontrados en los templos sumerios conocidos como zigurats, donde hay alusiones a sacerdotes que fueron reyes supremos no solos sirviendo a los dioses, sino también administrando las ciudades en nombre de ellos. ${ }^{24}$ Todo esto condujo a la nación a convertirse en el corazón espiritual e intelectual de la antigua Mesopotamia durante el primer milenio a. C.25

Basado en este marco histórico, es posible encontrar fuertes referencias a la intencionalidad del rey de intentar convertir a los jóvenes hebreos en representantes sacerdotales de la realeza babilonia. De esta manera, buscaba impactar sus concepciones culticas y su opinión de Dios para lograr de esta forma un mejor control de los asuntos religiosos de la nación. Esta postura se ampliará con mayor precisión en la siguiente sección.

\section{Aspectos litúrgicos/cultuales en relación al santuario-sacerdocio}

En el AT, los rituales frecuentemente se encontraban asociados a la protección de la naturaleza física, social, emocional o espiritual del recipiente, ${ }^{26}$ lo que podría estar marcado por su perspectiva idolatrareligiosa; siendo además percibida en forma de símbolos. ${ }^{27}$ Es en base a esta orientación, que se desprenderán los siguientes elementos encontrados en dicha pericopa.

21 Joseph Auneau, El sacerdocio en la Biblia (Navarra: Verbo Divino, 1990), 10-15.

22 Henrietta McCall, Mitos Mesopotámicos (Madrid: Ediciones Akal, 1994), 37.

23 Kautsky, El cristianismo, 237.

24 Migene González-Wippler, El libro de magia, hechizos y ceremonias (Woodbuty, MN: Llewellyn Español, 2000), 50.

25 Juan Luis Montero Fenollós, "Babilonia y Nabucodonosor: Historia antigua y tradición viva", Alberca 5 (2007): 171-188.

26 Warren A. Shipton, "Protección: coincidencias entre los principios científicos, rituales y morales", Dialogo Universitario 26, no. 2 (2014): 9-13.

27 Ralph Woodrow, Babilonia, misterio religioso: Antiguo y moderno (España: Clie, 2000), 2. 


\subsection{Casa/Templo}

La destrucción del templo de Jerusalén y la deportación de parte de su población, fue aparentemente una señal de subyugación no solo de Judá sino también de su Dios, quienes estaban ahora bajo el dominio del rey y los dioses babilónicos. ${ }^{29}$ De esta forma, el templo como lugar dedicado es entendido como centro principal del culto y lugar donde es celebrada la religión oficial, ${ }^{30}$ teniendo como estructura una planta rectangular, rodeada de un muro. ${ }^{31}$ Así, la sumisión al rey permitía a todos los dependientes del templo ser mantenidos por él, ${ }^{32}$ colocando los lugares de trabajo del panadero, cervecero y toda clase de artesanos en cubículos; manteniendo de esta manera el control de ellos a la vida sumeria. ${ }^{33}$ De allí que el contexto de Daniel 1 desarrolle la noción de traer a los cautivos al palacio del rey en

28 La sinagoga emerge en el templo durante el exilio babilónico como una reduplicación por la distancia y el templo destruido. Alfred J. Hoerth, Archaeology of the Old Testament (Grand Rapids: Baker Academic, 1998), 385. Por esta razón, fue importante y determinante la presencia de sacerdotes y profetas, como una plataforma para mantener su identidad y defender su anhelo de regresar. Luis Arturo García Dávalos, El carácter sacerdotal del pueblo de Dios: Paradigma para una comprensión eclesial (México: Universidad Iberoamericana, 2000), 150; José María Blázquez, Dioses, mitos y rituales de los semitas occidentales en la antigüedad (España: Cristiandad, 2001), 236.

29 Winfried Vogel, "Cultic Motifs and Themes in the Book of Daniel", JATS 7, no. 1 (1996): 28.

30 Ninian Smart, Las religiones del mundo (Madrid: Ediciones Akal, 2000), 201. Los templos más importantes son el Esagila y el Etemenanki. El Esagil o casa de la alta cúspide, era el santuario de Marduk, que había sido levantado con ladrillos. Este se encontraba organizado en torno al patio central. De esta manera, formaba parte de las fiestas y rituales en la ciudad a lo largo de los años. Sus habitaciones cuentan con mobiliario para las cuatro comidas cotidianas y excepcionales de los dioses que vivian o visitaban el santuario en las festividades. Montero Fenollós, "Babilonia y Nabucodonosor",175; Allan Bornape, “El problema del חרֶ en el Pentateuco y su dimensión ritual", DavarLogos 4, no.1 (2005): 1-16. Es también importante notar que el templo de Marduk en Babilonia era bastante espacioso. Timothy Monsma, “Jerusalén y Babilonia: Símbolos bíblicos para las ciudades", Reforma Siglo XXI, 2, no. 2 (2000): 23.

31 José María Blázquez Martínez, "Babilonia", Boletín de la Asociación Española de Oriente 39 (2003): 15-51.

32 J. A. Zamora López, "El sacerdocio próximo-oriental y los problemas de su estudio: Los sacerdotes mesopotámicos", en Entre Dios y los hombres: El sacerdocio en la antigüedad, Spal Monografías 7 (Sevilla: Secretariado de publicaciones de la Universidad de Sevilla, 2006), 40.

33 González-Wippler, El libro de magia, hechizos y ceremonias, 16. 
paralelo con traer los vasos del templo de Jerusalén a Babilonia. ${ }^{34}$ De esta manera se mostraba la condición de subordinación en la que se encontraban. ${ }^{35}$ Con esto en mente, es fácil entender la idea principal de todo el pasaje, al poner finalmente a Dios en una posición de superioridad frenta la soberanía y poderío del imperio babilonio. ${ }^{36}$ Esto se percibe mejor en el siguiente cuadro:

\section{Diferencias y semejanzas en conexión}

\section{Palacio/templo real}

הֵיכַל - 1:4

Sustantivo común masculino singular constructo. Esta frase acentúa el aspecto de muchas fortificaciones. ${ }^{37}$ También lo describe como una mansión o santuario, ${ }^{38}$ detallándose como un palacio (1 R 21:1), templo (2 $\mathrm{R}$ 18:16) o lugar santo (1 R 6:5). ${ }^{39}$ Ahora, como una mejor explicación de este lugar, es útil observar que en los usos extra-palestinos, esta palabra alude solamente al domicilio del rey. ${ }^{40}$

\section{Casa de los dioses o Dios como soberano}

בית - Daniel 1:2

Sustantivo común masculino singular constructo. El uso de esta palabra en el pasaje de estudio ocurre por lo menos 3 veces, ya sea en relación a la casa de Dios o en referencia a la casa de los dioses paganos. Esta alusión, confirmaría la idea anterior descrita, basada en la soberanía universal de Dios, independientemente del lugar en que se encuentren sus utensilios. Este edificio es construido para albergar a la divinidad y a sus servidores ya fueran sacerdotes y músicos. Esta palabra se usa de manera intercambiable como casa de Dios o templo. ${ }^{41}$

34 Joseph J. Collins, A Commentary on the Book Daniel, Hermeneia 27 (Philadelphia: Fortress, 1993), 124.

35 Wooden, The Book of Daniel and Manticism, 182.

36 W. Sibley Towner, Daniel, IBC (Atlanta: John Knox, 1994), 27; J. Jacobus de Bruyn, A Clash of Gods - Conceptualizing Space in Daniel 1, HTS Theological Studies 70, no. 3 (2014): 1-6.

37 Jenni Ernst, "בָּיִתית", Diccionario teológico: Manual del Antiguo Testamento, ed. Ernst Jenni y Claus Westerman (Madrid: Cristiandad, 1978), 1:450-451.

38 Luis Alonso Shökel, "הָיכָ", Diccionario bíblico hebreo-español (Madrid: Trotta, 1994), 200.

39 Moises Chávez, Diccionario de hebreo bíblico (El Paso, TX: Mundo Hispano, 1992), s.v. "היכָ", 152, 153.

40 Leonard J, Coopes, "הָיכָ", TWOT, 1:214.

41 H. A. Hoffner, "בָּית", TDOT, 2:111-112. 
Tales expresiones descritas en el cuadro, presentan vestigios de cómo Dios es soberano al manifestar su dominio y voluntad, a pesar de que el rey de Babilonia y sus súbditos doblegaron Jerusalén hasta destruirla. Obviamente, Dios acompañaba a los exiliados, a la vez que lo hace con cada utensilio deportado como resguardo de aquello que fue apartado para un uso santo. Pero, como acto humillante, el rey, en su función de representante de sus dioses, hacía de este hecho el acto mismo de presentar ante el mundo conocido todo lo que eran capaces de hacer, con tal de exaltar a sus divinidades a un nivel cultual-religioso de gran envergadura. A esto se suma las edificaciones religiosas opulentas, como medio de la realeza para sostenerse en el poder, convirtiendo la religión en el fundamento devoto de la vida Babilónica.

\section{סָריס - Eunuco}

Esta palabra hebrea que aparece en Daniel 1:3 está vinculada con el idioma acadio y describe el acto "de estar frente al rey" y no tiene necesariamente el concepto tradicional de eunuco, como suele ser traducido. ${ }^{42} \mathrm{Si}$ se le aplica esta última connotación a esta palabra, entonces el acto de cortar los testículos, al estar en referencia a Levítico 22:20, 21, 25; Números 18:2 y Deuteronomio 15:21, arrojaría argumentos descalificativos para que los tales ejercieran funciones culticas. ${ }^{43}$ Ahora, considerando el contexto de Daniel 1, sería incongruente que el rey los haya escogido sin tacha, para luego formar una anomalía en su cuerpo.

\subsection{Jóvenes, muchachos - ילְדִדים}

Este vocablo es usado en Daniel 1:4, posiblemente como una demostración de importancia para el proceso exiliar y es un término que hace alusión a niños, jóvenes y hombres jóvenes. ${ }^{44}$ No solo por el uso de esta palabra, sino también por el periodo de tiempo que supone las ocasiones en las que Daniel participó en diferentes momentos de la historia de Babilonia y Medo Persia, se cree que Daniel y sus amigos no tendrían más de 20 años cuando fueron llevados a Babilonia. ${ }^{45}$ Estos muchachos, estando en el exiio,

42 Alomía, Daniel, 25.

43 Wooden, The Book of Daniel and Manticism, 186.

44 Hay referencia a que la educación persa empezaba a los 14 años. Stephen R. Miller, Daniel, NAC 18 (Nashville: Broadman \& Holman, 1994), 60.

45 B. H. Carroll, Comentario bíblico: Daniel y el periodo intertestamentario (España: Clie, 1986), 5:31. Daniel tendría 18 años, una edad que era buena en la política babilónica para escoger cautivos. William H. Shea, Daniel: Una guía para el estudioso (Florida:

https://doi.org/10.17162/recm.v19i1.1473 
llegaron a ser objeto de una serie de pruebas complejas y fieras tentaciones. ${ }^{46}$ No obstante y pese a las circunstancias, defendieron los principios de la Escritura y la adoración al Dios verdadero aún a costa de su propia vida, lo cual los hace destacables, y todo gracias a la educación recibida en sus hogares. ${ }^{47}$

\subsection{Sin tacha - מָאוּם}

El uso de esta palabra hebrea refiere a jóvenes seleccionados, tanto para servir en el palacio del rey babilonio como en el de Jerusalén. Ellos califican por su elevada preparación al haber recibido toda la educación que fue necesaria, como útiles en el templo de Jerusalén para cumplir funciones de sacerdotes de Dios. Por lo tanto, estamos frente a un lenguaje cúltico o sacerdotal. ${ }^{48}$ Esta forma de referirse a los jóvenes hebreos describe su apariencia ampliamente atractiva y perfecta, y es vista no solo desde la perspectia estética sino también como característica de habilidad moral e intelectual. ${ }^{49}$ Así, se hace evidente una dinámica de comparación y competición; revelando los elementos de pureza, modelo, virtud y desarrollo personal. ${ }^{50}$

Asociación Casa Editora Sudamericana, 2009), 32. Las fuentes griegas antiguas y persas claman una educación similar de 3 a 4 años. Michael Whitworth, Derision of Heaven, 19-22.

46 Gerhard Pfandl, Daniel: The Seer of Babylon (Hagerstown, MD: Review \& Herald, 2004), 16; Richard D. Patterson, "Holding on to Daniel's Court Tales", JETS 36, no.4 (1993): 448.

47 Shipton, “La perspectiva de Daniel”, 13-17.

48 Donald E. Gowan, Daniel, AOTC (Nashville: Abingdon, 2001), 150. Al presentar una ofrenda para Dios como sacrificio, estas debían ser sin defecto alguno según Levítico 21:16-24; 22:19-21. Quizá el rey en su pretensión de ser dios, deseaba que estos se presentasen ante él, de la misma manera como ellos se presentaban ante Dios. C. L. Seow, Daniel, Westminster Bible Companion (Louisville: Westminster John Knox, 2003), 23. La palabra p̧וּ aparece 18 veces en el texto hebreo y en 5 ocasiones se relaciona al sacerdocio (Lv 21:17, 18, 21, 23) indicando que si alguno de los sacerdotes tenía algún defecto era descalificados para ofrecer sacrificios. Wooden, The Book of Daniel and Manticism, 185.

49 Hebbord, Reading Daniel, 67-70.

50 Shane Kirkpatrick, Competing for Honor: A Social-Scientific Reading of Daniel 1-6, BibInt 74 (Leiden: Brill, 2005), 196. 


\subsection{Lengua y cultura de los caldeos -

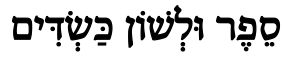

Esta expresión también se encuentra en Daniel 1:4. La referencia a los caldeos $^{51}$ fue observada de forma evidente en los monumentos babilonios, donde se nombra a una clase de sacerdotes de nombre galdu, quienes podrían ser los mismos caldeos referidos en Daniel. ${ }^{52}$ Así que, el hecho de que los jóvenes tengan como objetivo el aprendizaje de esta lengua y cultura de forma determinada, sería un intento de romper con la enseñanza de la Torá. Esto se debe a que las enseñanzas de los sacerdotes caldeos contradecían la creación y el diluvio, representando así, un cambio de fe para los cautivos. ${ }^{53}$ Esto los llevaría a aprender rituales, tradiciones y creencias babilónicas. ${ }^{44}$ Más aún, al hacer referencia al aprendizaje de la lengua sumeria, que era el idioma sagrado usado en los misteriosos rituales realizados por los sacerdotes, era necesario tomar años de estudio para su perfección..$^{55}$ Así, se mediatizaba la relación entre dioses y fieles. ${ }^{56}$

\subsection{Estar delante de o de pie en - לַממדד}

Esta expresión aparece en Daniel 1:4, 1:5 y 1:19. En el primer caso se describe la acción de estar en el templo, lo que es ampliado en los siguientes pasajes, con una representación directa de estar delante del rostro del rey. Esta palabra es vista también en Deuteronomio 10:8; 18:5 y 2 Crónicas 29:11. De estos ejemplos, se desprende la idea de lealtad a Dios, siendo así un vocablo técnico para los que están consagrados al servicio religioso. Por lo tanto, en el libro de Daniel los jóvenes hebreos ven amenazadas sus

51 Es posible que el texto no hable de los caldeos étnicos, sino de la comunidad sacerdotal de adivinos que en algún momento se conocieron como caldeos, es decir, una comunidad profesional. Walton, Matthews y Chavalas, Comentario al contexto cultural de la Biblia, 830.

52 Aalders, "The Book of Daniel", 242-254.

53 erry Robinson, "Daniel 1 Commentary", True Riches Radio, https://truerichesradio.com/daniel-1-commentary/ (consultado: 28 de octubre, 2021).

54 Michael Youssef, Leading the Way Through Daniel (Eugene, OR: Harvest House, 2012), 37.

55 D. S. Russell, Daniel, The Daily Study Bible Series (Edinburgh: Saint Andrew Press, 1981), 20. La religiosidad en Babilonia desemboca en la creencia del dominio de los astros, siendo esta una creencia sacerdotal tardía. Max Weber, Economía y sociedad (México: Edición Electrónica, 2014), 50.

56 Zamora López, “El sacerdocio próximo-oriental”, 40. 
acciones individuales, con el objetivo de convertirlos al culto de Nabucodonosor. ${ }^{57}$

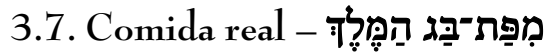

Otro de los elementos centrales en la narrativa de Daniel 1 es la comida. Tal referencia la encontramos en el v. 5 al describirse la alimentación dada a los jóvenes cautivos. Si consideramos los puntos anteriores donde se percibe un contexto cúltico, es posible conectar el asunto de la alimentación como parte del contexto del servicio de adoración. Por lo tanto, invitar a Daniel y sus amigos a participar de esta comida, implicaba sumisión al culto babilónico y reconocimiento de Nabucodonosor como dios. ${ }^{58}$ De esta forma, es usual que el rey ordenara una dieta específica, monitoreado por doctores y dietéticos en un intento por ajustarlos a las exigencias de perfección física y mental. ${ }^{59}$

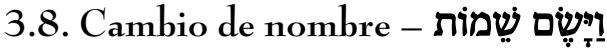

La intención de cambiar los nombres nos conduce a pensar en la aplicación mágica de la escritura. Esto se hace evidente al escribir su nueva identidad, dando a entender que el escritor ejercía un poder mágico sobre la persona. Este era solo un privilegio especial de los sacerdotes, ${ }^{60}$ ya que estos estaban mayormente involucrados en el acto de invocar el nombre de los dioses. De este modo, se usaba este método como medio de control para lograr un servicio exclusivo, garantizando así como amuleto; la protección de sus vidas y evitar ser erradicados por los dioses como se creía. ${ }^{61}$

57 Doukhan, Secretos de Daniel, 18; Carballosa, Daniel y el reino mesiánico, 45.

58 Carballosa, Daniel y el reino mesiánico, 45; Doukhan, Secretos de Daniel, 17; Daewoong Kim, Biblical Interpretation in the Book of Daniel: Literary Allusions in Daniel to Genesis and Ezekiel (Tesis doctoral, Rice University, 2013), 19.

59 Hersh Goldwurm, Daniel: A New Translation with a Commentary Anthologized from Talmud, Midrashic, and Rabbinic Sources (Jerusalén: Mesorah Publications, 1998), 63. En este pasaje se ve la idea de libación, consistiendo en una ofrenda de bebida en honor a la divinidad. José Luis Legonagoitia, "El vino en la religión y en la fiesta", Douro: Estudos \& Documentos 7, no. 13 (2002): 3.

60 Kautsky, El cristianismo, 15; Sinclair B. Ferguson, "Daniel”, en Nuevo Comentario Bíblico Siglo Veintiuno, ed. G. J. Wenham et al. (El Paso, TX: Casa Bautista de Publicaciones, 1999), 782.

61 Georges Contenau, La vida cotidiana en Babilonia y Asiria (Barcelona: Ediciones Mateu, 1958), 318; Tyndale House Publisher, The One Year Bible Companion: Question and Answers to Help You Make the Most of Your Daily Bible Reading (Carol Stream, IL: Tyndale House, 1992), 40. De esta manera se presenta el concepto de exaltación a los dioses 
Todos estos conceptos, solo confirman, avalan y hasta amplifican la fuerte y arraigada concepción religiosa de Daniel 1, conduciendo a pensar en una evaluación, investigación y formación de naturaleza sacerdotal en los jóvenes hebreos puestos a prueba, en medio del exilio.

\section{Conclusión}

Los diversos elementos cúlticos y rituales descritos, además de los factores históricos, en relación al santuario en Daniel 1, permiten observar la fuerte influencia de la religión en los aspectos sociales, reales y, desde luego, en la esfera sacerdotal. Es evidente que Nabucodonosor inició un plan de conducción de los jóvenes hebreos que implicaba un cambio de perspectiva en relación al Dios en quienes creían y a una ruptura de su concepción bíblica. Por esta razón, pareciera evidente que su principal esquema, a la hora de llevar cautivos a personas de Jerusalén en particular, proporcionaba las bases para una educación que los hiciera capaces, no solo de servir en la corte real, sino también en los aspectos cúlticos propios de la labor y linea sacerdotal. Probablemente esto encierra una aplicación que afectaría no solo en los aspectos de la realeza sino en aquellos en los que competía participar y conducir el culto, mostrando al rey que los jóvenes estaban facultados para ejercer idóneamente en donde se les necesitara al momento de cumplir sus funciones.

como medio para evitar los ataques de los dioses, cuando estos notaban que no se cumplían con sus exigencias. Matthew Janzen, "Commentary on Daniel: Chapters 16", http://www.ministersnewcovenant.org/uploads/9/1/6/1/9161032/commentary_ daniel_1-6.pdf (consultado: 01 de noviembre, 2021); David Guzik, “Daniel 1 - Keeping Pure in the Face of Adversity", Enduring Word, https://enduringword.com/biblecommentary/daniel-1/ (consultado: 01 de noviembre, 2021).

https://doi.org/10.17162/recm.v19i1.1473 